\title{
Asset Management of Embankment of Irrigation Tank
}

\begin{abstract}
Akira Kobayashi ${ }^{1}$, Kiyohito Yamamoto ${ }^{2}$ and Takuma Hayashi ${ }^{3}$
Abstract: To decide the timing and the method of repair of the irrigation tanks, the method to evaluate the life cycle cost (LCC) of the tank was proposed by using the annual failure probability and the amount of the loss which were derived from the disaster data at Awaji Island in 2004. It was found that as the tank was repaired at the earlier timing, LCC of the tank at the 80th year became lower when a single tank was examined. The effect of LCC was also influenced by the repair cost. As LCC of the multiple tanks in an area, the total LCC became large in the case that the maximum budget became small and the period of repair became long, while the investment effect became high. The uniform annual cost of repair could be planned if the repair of each tank was carried out in a single year or the budget of repair was restrained to relatively small value.
\end{abstract}

Keywords: Life cycle cost; Repair and maintenance; Embankment; Irrigation tank; Asset management

\section{Introduction}

There are about 210 thousands irrigation tanks in Japan, which have been the important sources of water supply for farming since ancient times. But most of the tanks were constructed many years ago and become too old. Kato (2005) reported that about 20 thousands tanks needed to be repaired. Due to the decrease in the population of farming areas and the increase of aging farmers, many tanks are not well kept. Under this circumstance, when a big earthquake or a heavy rain by typhoon is encountered, the failure probability of the embankment will be very high. Therefore, the maintenance and repair of the irrigation tank are the important problems. In general, the irrigation tanks in a local area are managed by a group of users and a local government. Because they are under a severe financial condition, it is necessary to plan the effective maintenance and repair. Therefore, the method of asset management has to be applied to the maintenance of irrigation tanks.

Asset management for public structures means that maintenance and repair are planned to be the most cost efficient, seeing the damage and deterioration of the structure for the future, and that the service is kept at the possible best situation. A number of studies have been conducted on the management. Odasawa et al. (2004) considered an economical and physical deteriorating process as Marcov process, including cost-benefit and life cycle cost, and formularized a model of asset management to decide an optimal repair strategy. Kong et al. (2003) developed a methodology for the evaluation of expected life cycle maintenance cost of deteriorating structures by considering uncertainties associated with the application of cyclic maintenance actions. Asset management mainly has been applied to a concrete structure since the deterioration of the concrete structure due to a salt damage or a neutralization can

${ }^{1}$ Associate Professor, Graduate School of Agriculture, Kyoto University, Kitashirakawa-oiwake-cho, Sakyo-ku, Kyoto 606- 8502, Japan (Corresponding Author) E-mail: kobadesu@kais.kyoto-u.ac.jp

${ }^{2}$ Assistant, Graduate School of Agriculture, Kyoto University, Kitashirakawa-oiwake-cho, Sakyo-ku, Kyoto 606-8502, Japan

${ }^{3}$ MC student, Graduate School of Agriculture, Kyoto University, Kitashirakawa-oiwake-cho, Sakyo-ku, Kyoto 606-8502, Japan be predicted. On the other hand, more researches are necessary for earth structures like an embankment of an irrigation tank, because it is difficult to predict the deteriorating process quantitatively. Deterioration of an earth structure is not understood well. Therefore, instead of deterioration of the structure, the increase of the failure probability due to the increase of the probability to encounter the disaster is considered in this study.

In 2004, ten typhoons hit Japan. One of them hit the Awaji Island. Over 180 embankments of irrigation tanks in the island were failed by overflow due to heavy downpour (Japanese Society of Irrigation, Drainage and Reclamation Engineering, Kyoto branch, 2005). Kobayashi et al. (2006) developed the method to predict the probability and the loss of the failure of irrigation tanks by using the assessment result of restoration, the database of irrigation tanks and the geographical information system (GIS) with digital elevation model (DEM) from satellite picture at Awaji Island. By using the method to predict the risk, LCC of a tank can be estimated by considering the probability and the loss. In this study, the effect of the timing of repair on LCC is firstly examined for a single tank. Secondly, the method of asset management of the multiple tanks is introduced by using the same method. As mentioned earlier, the method used in the study does not consider the deterioration of a structure but the probability to encounter the heavy rain. The selected repair method is, therefore, assumed to reduce the risk of failure due to overflow of the embankment. However, the similar discussion for deterioration increasing the failure risk will be carried out by replacing to the relation between repair and reduction of risk for deterioration.

\section{Risk and life cycle cost}

\subsection{Failure probability}

Firstly, the method used in this study to estimate the LCC (Kobayashi et al., 2007) is briefly introduced. By using the information of the failed embankment in Awaji Island in 
2004, the discriminant analysis by Mahalanobis' distance was carried out. The resultant explaining variables are shown in Table 1. Although the capacity of a spill way is not included in the table, the variable was cancelled out through the analysis. This is probably because the usage condition of spill way was not good and the performance was not exerted at the disaster. To calculate the annual failure probability, only the effective rainfall was assumed to have a temporal change. The conditional failure probability as a function of effective rainfall (half life of 72 hours), $P_{C}(x)$, can be calculated for an embankment as

$$
P_{C}(x)=\frac{1}{1+\exp (\alpha x+\beta)}
$$

where $\alpha$ and $\beta$ are the parameters decided for each embankment from the discriminant analysis. $x$ is the effective rain fall. Figure 1 shows the example of the conditional failure probability. The failure probability increases with effective rainfall. It is found in the figure that the failure probability is not zero at zero effective rainfall. The failure probability is overestimated for the effective rainfall smaller than a few hundreds millimeters because the probability is obtained by extrapolating from the failure at the effective rainfall of a few hundreds millimeters. Then, by using the probability density function of effective rainfall, $f(x)$, shown in Figure 2 which was calculated with the data for 30 years, the annual failure probability $P_{Y}$ was obtained for each embankment by

$$
P_{Y}=\int_{0}^{\infty} P_{C}(x) f(x) d x
$$

\subsection{Loss Prediction and annual risk}

The amount of loss consists of the cost to restore and the loss for inability of farming for a single year. By the regression analysis using the result of restoration assessment, the regression equation using the explaining variables shown in Table 2 was obtained, which showed that the large embankment having a wide crest, high height and large area of basin had a large amount of the loss. The cost to restore for each embankment can be predicted by the equation of regression. The loss by inability of farming for a single year is obtained by the following equation;

The loss by inability of farming =

(Area using water from the irrigation tank)

$\times$ (The price of rice per unit weight)

$\times$ (The weight of rice per unit area)

where the area using water from the irrigation tank is deduced from the database of tanks. The annual loss, $C$, is obtained by summation of the cost of restoration and annual loss of farming. The annual risk $R$ is the product of the annual failure probability and the amount of the loss.

\subsection{Life cycle cost}

Since the life of the earth structure as the irrigation tank is long, we have to consider the cumulative risk. For example,

\begin{tabular}{|c|c|c|}
\hline $\begin{array}{l}\text { Number of } \\
\text { tanks }\end{array}$ & & 1516 \\
\hline \multirow{9}{*}{$\begin{array}{c}\text { Explanation } \\
\text { variables }\end{array}$} & $x_{1}$ & Width of crest (m) \\
\hline & & Height of embankment (m) \\
\hline & $\overline{x_{3}}$ & $\begin{array}{l}\text { Downstream Slope of embankment } \\
\text { (ratio of horizontal distance to } \\
\text { height) }\end{array}$ \\
\hline & & Total storage capacity $\left(\mathrm{m}^{3}\right)$ \\
\hline & & Intake capacity $\left(\mathrm{m}^{3} / \mathrm{s}\right)$ \\
\hline & $x_{6}$ & $\begin{array}{l}\text { Average angle of inclination in ba- } \\
\sin \text { (deg.) }\end{array}$ \\
\hline & $\overline{x_{7}}$ & $\begin{array}{l}\text { Standard deviation of angle of } \\
\text { inclination in basin (deg.) }\end{array}$ \\
\hline & & Vegetation index in basin \\
\hline & & $\begin{array}{l}\text { Effective rainfall (half life of } 72 \\
\text { hours) (mm) }\end{array}$ \\
\hline
\end{tabular}

Table 1: Variables for discriminant analysis

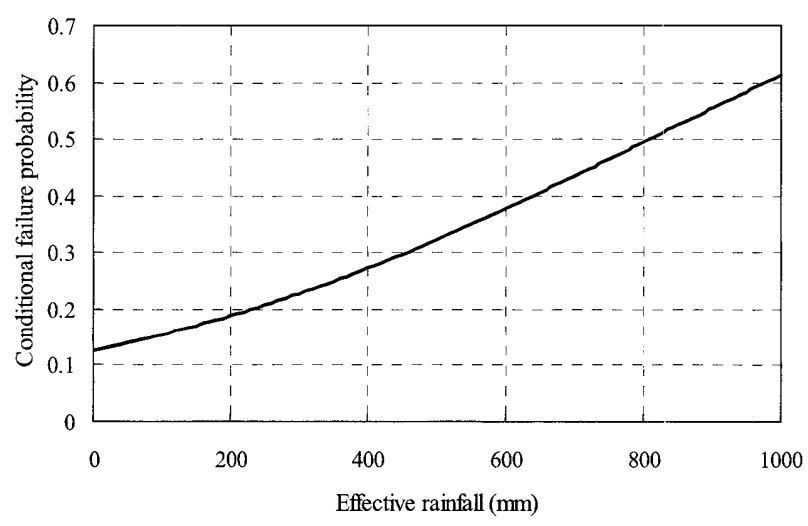

Figure 1: Example of conditional failure probability, $P_{C}$

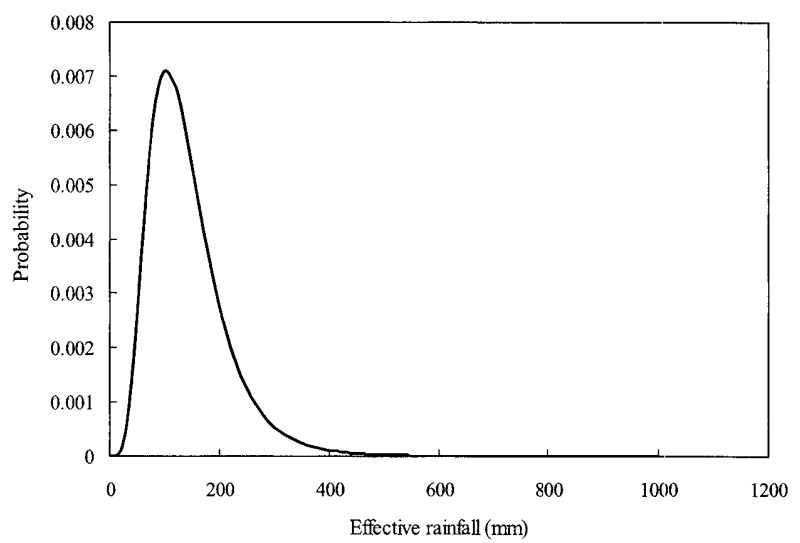

Figure 2: Probability density function of effective rainfall, $f$

Table 2: Variables for multiple regression analysis

\begin{tabular}{ccc}
\hline Number of tanks & & \multicolumn{1}{c}{45} \\
\hline \multirow{2}{*}{\begin{tabular}{c} 
Explanation vari- $\begin{array}{c}\text { ables } \\
\text { abl }\end{array}$ \\
\cline { 2 - 3 }
\end{tabular}} & $x_{1}$ & Width of crest (m) \\
\cline { 2 - 3 } & $x_{2}$ & Height of embankment (m) \\
\hline
\end{tabular}


given the annual failure probability of $P_{Y}$ and the annual risk $R$, the risk at the $i$ th year $R_{i}$ can be written by the following equation;

$$
R_{i}=\left(1-P_{Y}\right)^{i-1} \times R \times\left(\frac{1}{1+\rho}\right)^{i-1}
$$

$\rho$ is the discount rate which is 0.04 in Japan, representing the discount on the future cash flow (Ministry of Land, Infrastructure, Transport and Tourism, 2004). If the embankment is repaired at the 10th year and the risk after repair is $R_{R}$, the risk at the 20th year is given by using the failure probability after repair, $P_{R}$ as

$$
R_{20}=\left(1-P_{Y}\right)^{9} \times\left(1-P_{R}\right)^{10} \times R_{R} \times\left(\frac{1}{1+\rho}\right)^{19}
$$

The risk of the $i$ th year is dependent on the repairing method and the timing of repair. The cumulative risk for $N$ years, $R_{N}^{\prime}$ is given by the following equation;

$$
R_{N}^{\prime}=R_{1}+R_{2}+\cdots+R_{N}
$$

LCC is given by adding the repair cost $C_{R}$ to $R_{N}^{\prime}$. It is notable that the cost of repair has to be reduced to the present value by using the discount rate. For an example, LCC at the 20th year is given by the following equation for the case that the repair is carried out at the 10 th year.

$$
\begin{aligned}
& L C C=R+\frac{\left(1-P_{Y}\right)}{(1+\rho)} \times R+\cdots+\frac{\left(1-P_{Y}\right)^{8}}{(1+\rho)^{8}} \times R+ \\
& \frac{\left(1-P_{Y}\right)^{9}}{(1+\rho)^{9}} \times R_{R}+\frac{\left(1-P_{Y}\right)^{9} \times\left(1-P_{R}\right)}{(1+\rho)^{10}} \times R_{R} \\
& +\cdots+\frac{\left(1-P_{Y}\right)^{9} \times\left(1-P_{R}\right)^{10}}{(1+\rho)^{19}} \times R_{R}+C_{R} \times \frac{1}{(1+\rho)^{9}}
\end{aligned}
$$

The best measure is selected to make LCC at the $N$ th year the lowest. The number of years when LCC is examined is dependent on the structure. LCC of the irrigation tank is that for 80 years (Ministry of Agriculture, Forestry and Fisheries of Japan, 1985). However, the duration of the past service until the present is not known for many irrigation tanks. Since the service of the tanks is expected for a long future regardless of the duration of past service, LCC at the 80th years from the present is evaluated in this study. If the multiple tanks are considered, the total LCC after 80 years from the present is examined.

\section{Measure for failure of embankment}

\subsection{Strategy of repair}

From the results of the risk prediction mentioned above, it was found that the failure probability of an embankment decreased by widening the crest of the embankment and decreasing the gradient of the downstream slope which was the angle from the vertical line. While decreasing the height of the embankment also decreased the failure probability, the measure is impossible in the practical sense. If there are the other measures of which the change in the failure probability can be evaluated, the measure may become the candidate. The study about the change in the failure probability of the measures has not been carried out so much. Therefore the repair of widening the crest by $\Delta x \mathrm{~m}$ is assumed to be performed in this study. Since the position of toe of the downstream slope is not changed, the gradient of the downstream slope becomes steep by widening the crest. However, from the point of view of the stability of the slope, the minimum gradient is assumed to be $45^{\circ}$ in this paper. The possible widening of the crest is constrained by this limit. by;

Referring to Figure 3, the volume of repair, $\Delta V$ is given

$$
\Delta V=\frac{\Delta x \times \text { Height }}{2} \times \text { Length }\left(\mathrm{m}^{3}\right)
$$

To examine the cost of repair, the cost for unit volume is estimated from the result of restoration examination. The average cost of restoration was about 3,000 yen per unit volume of an embankment at the disaster in Awaji Island. The cost of repair is estimated by multiplying the volume of repair by the average cost per unit volume for restoration. While the above unit cost may be low as an actual repair, the effectiveness of repair on LCC is discussed by the ratio of LCC and repair cost. The effectiveness of the repair on

\begin{tabular}{|c|c|c|c|c|c|c|c|c|c|c|}
\hline$\underline{\operatorname{tank}}$ & $\begin{array}{l}x_{1} \\
\mathrm{~m} \\
\end{array}$ & $\begin{array}{l}x_{2} \\
\mathrm{~m} \\
\end{array}$ & $x_{3}$ & $\begin{array}{l}x_{4} \\
\mathrm{~m}^{3} \\
\end{array}$ & $\begin{array}{c}x_{5} \\
\mathrm{~m}^{3} / \mathrm{s} \\
\end{array}$ & $\begin{array}{c}x_{6} \\
\text { deg. }\end{array}$ & $\begin{array}{c}x_{7} \\
\text { deg. }\end{array}$ & $\begin{array}{c}x_{8} \\
N D V I \\
\end{array}$ & $\begin{array}{c}x_{9} \\
\mathrm{~mm}\end{array}$ & $\begin{array}{l}x_{10} \\
\text { ha }\end{array}$ \\
\hline$\underline{\mathrm{K}}$ & 3.5 & 9.3 & 1.7 & 6000 & 0.01 & 26.8 & 12.3 & 0.30 & 261 & 6 \\
\hline$\underline{F}$ & 6 & 7 & 1.6 & 6825 & 0.03 & 28.7 & 11.6 & 0.26 & 261 & 1 \\
\hline$\underline{G}$ & 8.2 & 7 & 1.4 & 2000 & 0.04 & 28.0 & 12.6 & 0.30 & 261 & 2 \\
\hline$\underline{Y}$ & 3.3 & 5 & 1.5 & 562 & 0.01 & 24.9 & 10.9 & 0.24 & 261 & 1 \\
\hline$\underline{S}$ & 2 & 1.8 & 1.2 & 48 & 0.01 & 24.2 & 12.0 & 0.28 & 261 & 1 \\
\hline$\underline{B}$ & 2 & 3 & 1.3 & 413 & 0.01 & 26.8 & 11.0 & 0.29 & 261 & 1 \\
\hline$\underline{\mathrm{A}}$ & 2.8 & 4 & 1.5 & 672 & 0.01 & 22.5 & 10.3 & 0.30 & 237 & 1 \\
\hline C & 6 & 3 & 1.5 & 338 & 0.06 & 26.3 & 10.6 & 0.17 & 261 & 1 \\
\hline
\end{tabular}
LCC is examined in this study.

\subsection{Conditions of tanks and assessment results} In this study, the management for eight irrigation tanks in

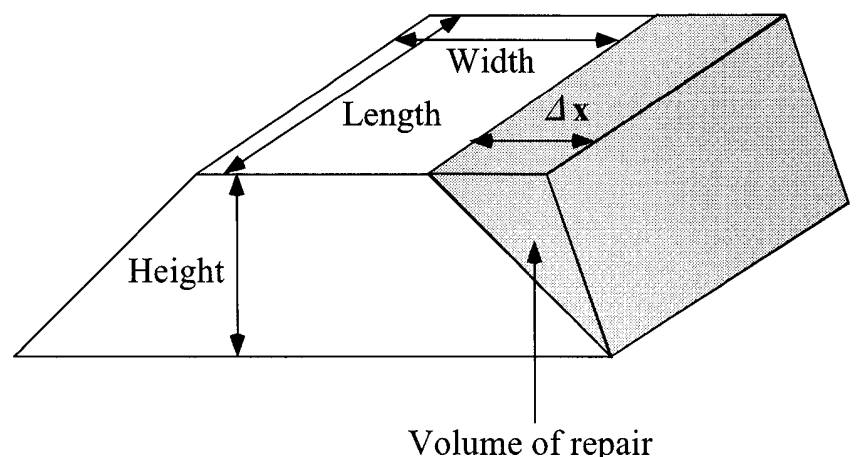

Figure 3: Repair by widening the crest

Table3: Variables used to estimate the risk of each tank 
Table 4: Results of assessment of each tank

\begin{tabular}{lccccccc}
\hline & $P_{Y}$ & $\begin{array}{c}R \\
10^{3} \text { Yen }\end{array}$ & $\begin{array}{c}\Delta x \\
\mathrm{~m}\end{array}$ & $\begin{array}{c}\Delta V \\
\mathrm{~m}^{3}\end{array}$ & $\begin{array}{c}C_{R} \\
10^{3} \text { Yen }\end{array}$ & $P_{R}$ & $\begin{array}{c}R_{R} \\
10^{3} \text { Yen }\end{array}$ \\
\hline $\mathrm{K}$ & 0.06 & 2541 & 5 & 1581 & 4743 & 0.01 & 945 \\
\hline $\mathrm{F}$ & 0.04 & 1212 & 5 & 788 & 2363 & 0.004 & 252 \\
\hline $\mathrm{G}$ & 0.02 & 981 & 5 & 735 & 2258 & 0.002 & 149 \\
\hline $\mathrm{Y}$ & 0.05 & 549 & 5 & 281 & 844 & 0.01 & 224 \\
\hline $\mathrm{S}$ & 0.06 & 173 & 2.5 & 63 & 189 & 0.04 & 113 \\
\hline $\mathrm{B}$ & 0.06 & 164 & 1.2 & 63 & 189 & 0.04 & 84 \\
\hline $\mathrm{A}$ & 0.04 & 615 & 2.5 & 110 & 330 & 0.01 & 318 \\
\hline $\mathrm{C}$ & 0.03 & 578 & 3 & 122 & 365 & 0.01 & 228 \\
\hline
\end{tabular}

Table 5: LCC for various timing for repair of $\mathrm{G}$ tank

\begin{tabular}{lc}
\hline Timing & $\begin{array}{c}\text { LCC at } 80^{\text {th }} \text { year } \\
(\times 103 \text { yen })\end{array}$ \\
\hline No repair & 16,367 \\
\hline $5 \mathrm{~m}$ widening at $1^{\text {st }}$ year & 5,790 \\
\hline $5 \mathrm{~m}$ widening at $20^{\text {th }}$ year & 13,469 \\
\hline $1 \mathrm{~m}$ widening every 4 years & 8,402 \\
\hline
\end{tabular}

an area is examined. These tanks actually exist in an area of Awaji Island. LCC of each tank is estimated by using the database and the geographical information. Table 3 shows the values of variables shown in Tables 1 and 2 of each tank used to estimate the risk. Table 4 shows the annual failure probability before repair $P_{Y}$, the annual risk before repair $R$, the amount of widening $\Delta x$, the volume to repair $\Delta V$, the cost to repair $C_{R}$, the annual failure after repair $P_{R}$ and the annual risk after repair $R_{R}$ of each tank. The amount of widening of each tank for repair is decided according to the above procedure. The total cost for repair is 11,279 thousands yen. If the budget corresponding to the total cost can be provided, it is the best measure to repair all the tanks in a single year. However, in the case that the annual budget is restricted, it is necessary to examine the order of repair to reduce the total LCC of tanks in an area. In this study, the investment effect on LCC is also examined.

\section{Asset management of tanks}

\subsection{Single tank}

Firstly, the effect of the timing of repair is examined by using the data about $\mathrm{G}$ tank. Table 5 shows LCC at the 80th years from the present for various timings of repair. If the repair is carried out at the 1 st year, LCC becomes the smallest. In the case that the repair is carried out after 20 years, LCC becomes high. It is a general tendency that LCC becomes smaller as the timing of repair is earlier. If the repair is carried out by widening the crest by $1 \mathrm{~m}$ every 4years until the 16th years after the repair at the 1 st year, LCC becomes the medium of above both cases. In this case, the failure probability becomes small gradually by widening the crest of embankment. This case means the selection of the measure by which the failure probability is decreased by holding down the annual spending for the repair.

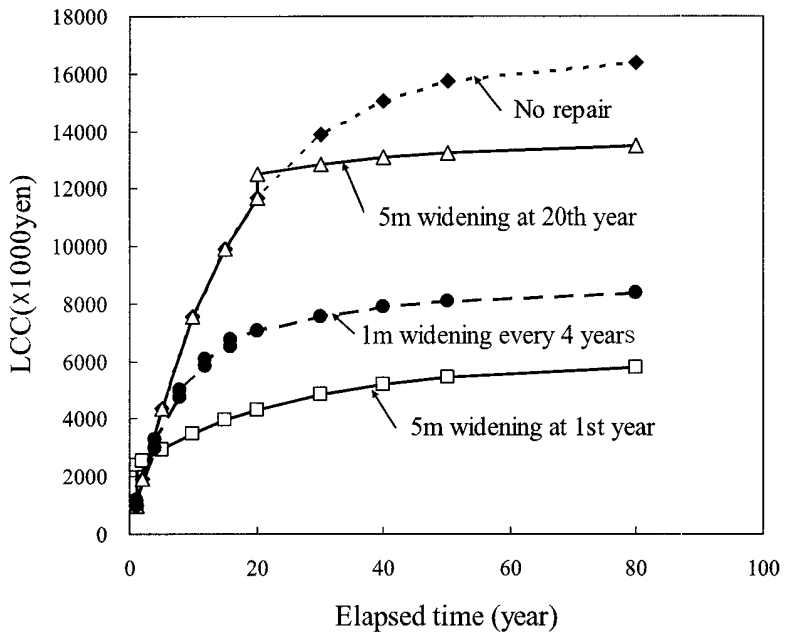

(a) During 80 years

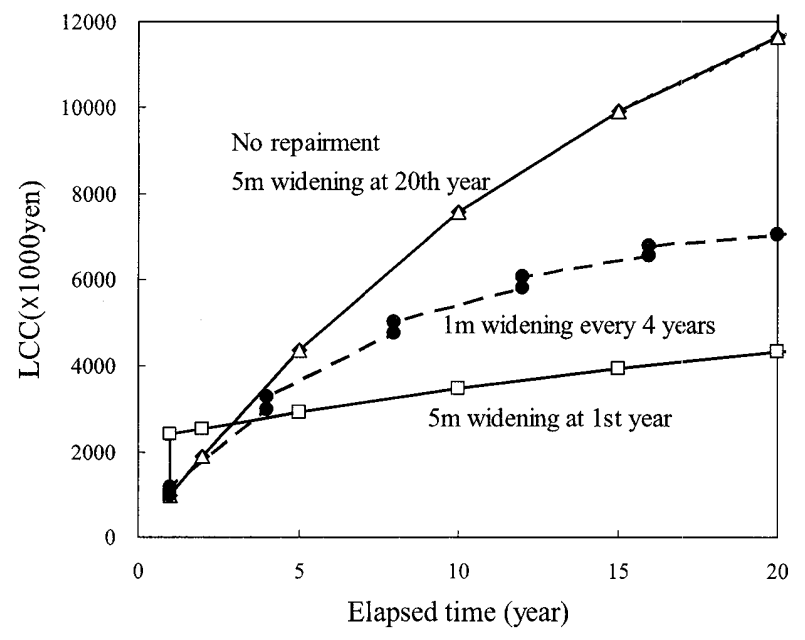

(b) Detail behaviors during 20 years

Figure 4: Life cycle cost for various repair strategies ( 3,000 yen per unit volume)

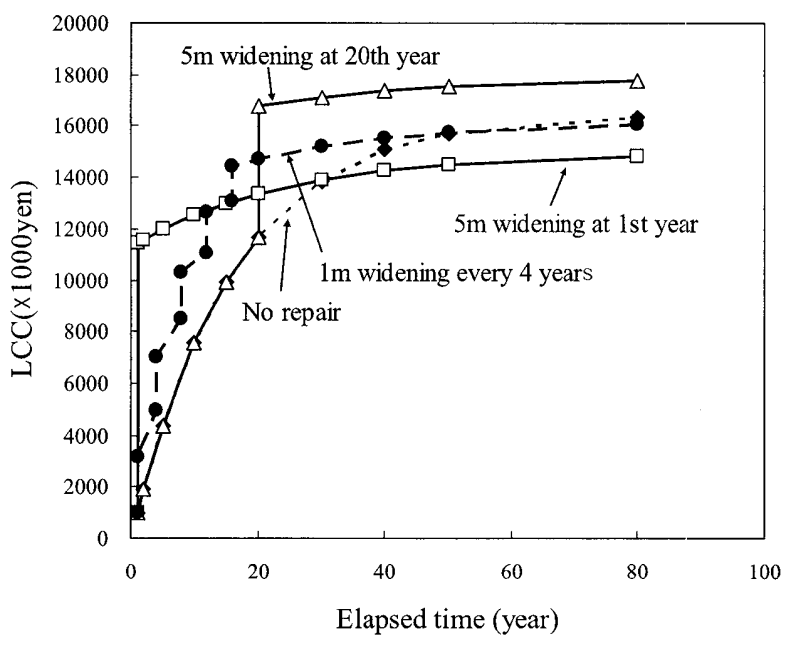

Figure 5: Life cycle cost for various repair strategies (15,000 yen per unit volume) 
Figure 4 shows LCC for each case as a function of time. The detail change for 20 years is indicated in Figure 4 (b). If the repair is carried out at the 1st year, LCC is larger than that of no repair case until the 3rd year. The period that LCC by the repair at the 1st year is larger than that of no repair case is dependent on the unit cost of repair. Figure 5 shows the results in the case of 15,000 yen per unit volume for repair. If the repair is carried out at the 20th year, LCC for 80 years becomes larger than that of no repair case. Even if the repair is carried out at the 1st year, LCC is larger than that of no repair case until the 30th year, and LCC at the 80th years is not so different from LCC of no repair case. It is found that LCC is not improved by the repair so much if the repair cost is quite larger than the loss by failure. It is, however, concluded in spite of the repair cost that LCC is improved as the timing of repair becomes early.

\subsection{Multiple tanks}

\subsubsection{Examination cases}

The asset management of eight irrigation tanks shown in the previous chapter is examined. The repair by widening the crest is also considered in this section. The length of widening of each embankment is shown as $\Delta x$ in Table 4. The cost of repair is given by $C_{R}$ if widening is carried out by the length. $C_{R}$ in the table is calculated by using the cost of 3,000 yen per unit volume for repair. As mentioned earlier, the asset management is carried out to make the total of LCC of eight tanks at the 80th year from the present be the lowest. In the case that the annual budget for repair is limited, the order of repair of each tank has to be examined. If the maximum annual budget is larger than the most expensive repair cost among the tanks, all tanks can be repaired in 1 year. In this case, the order of repair is examined. However, if the annual budget is smaller than the repair cost of a tank, the repair for the tank has to be carried out by dividing the cost into the multiple years. Among eight tanks, K, F and $G$ tanks have a relatively high repair cost as shown in Table 4. The length of widening crest is $5 \mathrm{~m}$ for those tanks. If the repair is divided into 5 years, the repair is carried out by widening the crest by $1 \mathrm{~m}$ every year for 5 years. The cost every year is assumed to be the one fifth of the repair cost shown in Table 4.

From the above consideration, three cases shown in Table 6 are examined in the study. Case A is the case that the maximum annual budget is larger than the repair cost of $\mathrm{K}$ tank. If the annual budget becomes large in this case, the number of years of repair for all tanks becomes small because the number of tanks repaired in 1 year becomes large.

Case B is the case that the repair of the tank having the most expensive repair cost is divided into 5 years as mentioned above. The other tanks are repaired in 1 year. This case can reduce the annual budget than Case $\mathrm{A}$.

Case $\mathrm{C}$ is the case that the repair of $\mathrm{K}, \mathrm{F}$ and $\mathrm{G}$ tanks is divided into 5 years. This case can make the annual budget smaller than Case B, while the number of years of repair is extended.

\subsubsection{Examination method}

The annual cost of repair of each tank can be calculated in each case. If the annual budget is limited, the number of tanks repaired in 1 year is constrained. With the assumption that the repair is started from the 1st year and all ranks are repaired continuously without break, all the combinations of start time of repair are examined and the comparison of total LCC of eight tanks at the 80th year from the present is carried out. The combination of start time of repair giving the lowest total LCC is determined. For all cases shown in Table 6, the effect of annual budget is examined by changing the maximum budget.

\subsubsection{Examination results}

\subsubsection{Case A}

In this case, the lowest maximum annual budget is 4,743 thousands yen, which is corresponding to the repair cost of $\mathrm{K}$ tank. The other tanks are not repaired at the year when $\mathrm{K}$ tank is repaired. If the budget is increased, the number of tanks repaired in a single year is increased. Table 7 shows the examination result. The number for each tank indicates the year of repair. LCC and the repair cost are the total costs of eight tanks, which are converted to the present money value. For example, in the case of annual budget of 4,743 thousands yen, $\mathrm{F}$ and $\mathrm{G}$ tanks are repaired at the 1 st year, $\mathrm{Y}$, $\mathrm{S}, \mathrm{B}, \mathrm{A}$, and $\mathrm{C}$ tanks are repaired at the 2 nd year, and $\mathrm{K}$ tank is repaired at the 3 rd year. This order of repair gives the lowest LCC at the 80th year from the present. If the maximum budget is 12,000 thousands yen, all the tanks can be repaired at the 1st year and the total LCC of eight tanks

Table 6: Examination cases

\begin{tabular}{cl}
\hline Case & \multicolumn{1}{c}{ Description } \\
\hline A & $\begin{array}{l}\text { The maximum annual budget is larger than } \\
4,743 \text { thousands yen. Thus, the combination of } \\
\text { tanks to be repaired at each year is examined. }\end{array}$ \\
\hline B & $\begin{array}{l}\text { The repair of } \mathrm{K} \text { tanks is divided into } 5 \text { years. } \\
\text { The other tanks are repaired in 1 year. }\end{array}$ \\
\hline C & $\begin{array}{l}\text { The repair of } \mathrm{K}, \mathrm{F} \text { and } \mathrm{G} \text { tanks is divided into } \\
5 \text { years. The other tanks are repaired in 1 year. }\end{array}$ \\
\hline
\end{tabular}

Table 7: Examination results of Case A

\begin{tabular}{|c|c|c|c|c|c|c|}
\hline $\begin{array}{l}\text { Maximu } \\
\text { budget* }\end{array}$ & & 12,000 & 10,000 & 8,000 & 6,000 & 4,743 \\
\hline \multirow{8}{*}{$\begin{array}{l}\text { Start } \\
\text { time to } \\
\text { repair } \\
\text { each } \\
\text { tank }\end{array}$} & $\mathrm{K}$ & 1 & 1 & 2 & 2 & 3 \\
\hline & $\mathrm{F}$ & 1 & 1 & 1 & 1 & 1 \\
\hline & $\mathrm{G}$ & 1 & 1 & 1 & 1 & 1 \\
\hline & $\mathrm{Y}$ & 1 & 2 & 1 & 2 & 2 \\
\hline & $\mathrm{S}$ & 1 & 2 & 1 & 1 & 2 \\
\hline & $\mathrm{B}$ & 1 & 1 & 1 & 1 & 2 \\
\hline & $\mathrm{A}$ & 1 & 2 & 1 & 1 & 2 \\
\hline & $\mathrm{C}$ & 1 & 1 & 1 & 1 & 2 \\
\hline \multicolumn{2}{|l|}{$\mathrm{LCC}^{*}$} & 57,737 & 57,954 & 58,346 & 58,415 & 59,372 \\
\hline \multicolumn{2}{|c|}{ Repair cost* } & 11,279 & 11,227 & 11,097 & 11,064 & 10,848 \\
\hline \multicolumn{2}{|c|}{ Repair/LCC } & 0.195 & 0.194 & 0.190 & 0.189 & 0.183 \\
\hline
\end{tabular}




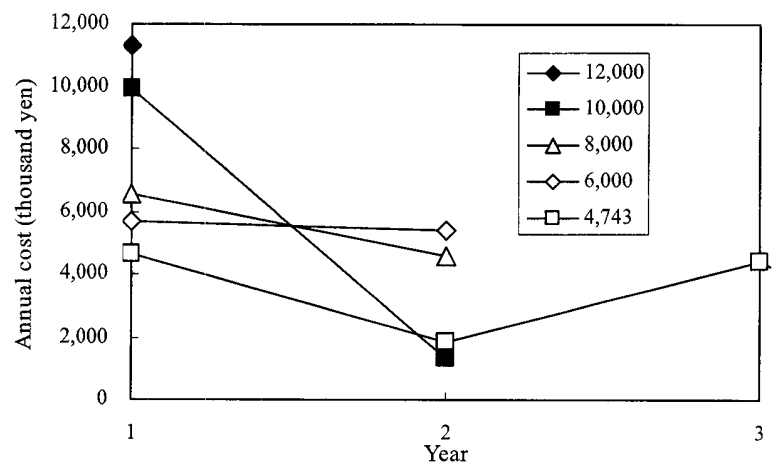

Figure 6: Annual cost of repair for each maximum budget in Case A (Caption is the maximum budget (thousands yen))

Table 8: Examination results of Case $\mathrm{B}$

\begin{tabular}{|c|c|c|c|c|c|c|}
\hline $\begin{array}{l}\text { Maximu } \\
\text { budget* }\end{array}$ & & 8,000 & 6,000 & 4,743 & 3,500 & 2,500 \\
\hline \multirow{8}{*}{$\begin{array}{l}\text { Start } \\
\text { time to } \\
\text { repair } \\
\text { each } \\
\text { tank }\end{array}$} & $\mathrm{K}$ & 1 & 1 & 1 & 2 & 3 \\
\hline & $\mathrm{F}$ & 1 & 1 & 1 & 1 & 2 \\
\hline & $\mathrm{G}$ & 1 & 1 & 2 & 2 & 1 \\
\hline & $\mathrm{Y}$ & 1 & 2 & 2 & 3 & 3 \\
\hline & $\mathrm{S}$ & 1 & 2 & 1 & 1 & 4 \\
\hline & $\mathrm{B}$ & 1 & 2 & 1 & 1 & 1 \\
\hline & $\mathrm{A}$ & 1 & 2 & 1 & 1 & 3 \\
\hline & $\mathrm{C}$ & 1 & 1 & 1 & 1 & 3 \\
\hline \multicolumn{2}{|l|}{ LCC* } & 63,200 & 63,502 & 63,947 & 64,390 & 65,467 \\
\hline \multicolumn{2}{|c|}{ Repair cost* } & 10,928 & 10,868 & 10,809 & 10,609 & 10,369 \\
\hline \multicolumn{2}{|c|}{ Repair/LCC } & 0.173 & 0.171 & 0.169 & 0.165 & 0.158 \\
\hline
\end{tabular}

*: Budget and cost $\left(\times 10^{3}\right.$ yen $)$

becomes the smallest. However, the total repair cost becomes the highest. The last line shows the ratio of the repair cost to LCC, which means the investment effect of repair. If the value is small, the effect of repair on LCC is high. The case requiring a long period to finish the repair of all tanks shows a high investment effect, while LCC becomes high. This is the effect of discount ratio indicated in Equation (7).

Figure 6 shows the annual cost for repair. The cost at the 1 st year is the highest through all duration. While the case of the maximum budget of 10,000 thousands yen has the different costs between the 1st and 2nd year, the other cases show the balanced costs during duration.

\subsubsection{Case B}

In this case, the repair cost of $\mathrm{F}$ tank is the highest. It is assumed that $\mathrm{K}$ tank is repaired continuously for five years. Therefore, the end year of all repairs becomes long. For example, the case of annual budget is 3,500 thousands yen has a schedule shown in Figure 7 and the end year is the 6th year from the present. As the maximum budget becomes smaller, the period of repair becomes longer as shown in Table 8. By dividing the repair of $\mathrm{K}$ tank into 5 years, the maximum budget can be reduced. As the maximum budget

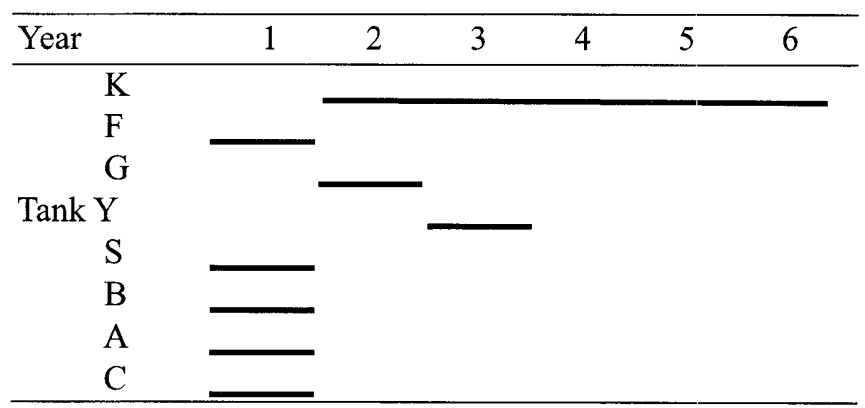

Figure 7: Schedule of repair in the maximum budget of 3,500 thousands yen

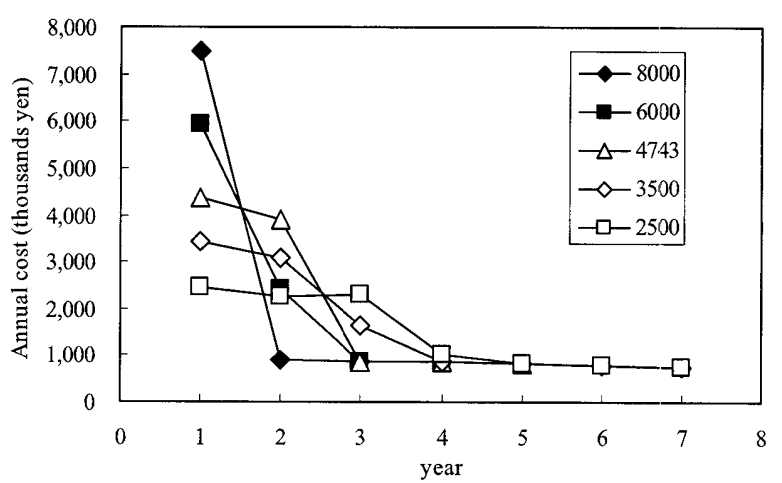

Figure 8: Annual cost of repair for each maximum budget in Case B (Caption is the maximum budget (thousands yen))

Table 9: Examination results of Case $\mathrm{C}$

\begin{tabular}{lcccccc}
\hline $\begin{array}{l}\text { Maximum } \\
\text { budget* }\end{array}$ & 4,743 & 3,500 & 2,500 & 1,500 & 1,000 \\
\hline \multirow{4}{*}{$\begin{array}{l}\text { Start } \\
\text { time to }\end{array}$} & $\mathrm{K}$ & 1 & 1 & 1 & 7 & 9 \\
\cline { 2 - 7 } $\begin{array}{l}\text { repair } \\
\text { each } \\
\text { tank }\end{array}$ & $\mathrm{F}$ & 1 & 1 & 1 & 1 & 2 \\
\cline { 2 - 7 } & $\mathrm{Y}$ & 1 & 1 & 1 & 1 & 2 \\
\cline { 2 - 7 } & $\mathrm{S}$ & 1 & 1 & 2 & 2 & 8 \\
\cline { 2 - 7 } & $\mathrm{B}$ & 1 & 1 & 1 & 1 & 1 \\
\cline { 2 - 7 } & $\mathrm{C}$ & 1 & 1 & 1 & 1 & 1 \\
\hline LCC* & & 68,139 & 68,207 & 68,559 & 70,261 & 71,612 \\
\hline Repair cost* & 10,586 & 10,554 & 10,416 & 9,495 & 9,017 \\
\hline Repair /LCC & 0.155 & 0.155 & 0.152 & 0.135 & 0.126 \\
\hline *: Budget and cost $\left(\times 10^{3}\right.$ yen) & & &
\end{tabular}

is reduced, the total LCC of eight tanks at the 80th year becomes large. However, the investment effect becomes good. In comparison with the results of Case A, the total LCC becomes larger than that of Case A while the investment effect is improved.

In this case, the annual cost of repair is changed during the duration of repair as shown in Figure 8. The annual cost at the 1st year is the highest during duration and that at the following years becomes small gradually. 


\subsubsection{Case $C$}

In this case, the maximum budget can be reduced more than that of Case B as shown in Table 9. Similarly to Case B, as the maximum budget becomes smaller, LCC becomes larger and the investment effect becomes better.

In this case, the period of repair becomes very long in comparison with Case B. Figure 9 shows the schedule of the case of the maximum budget of 1,500 thousands yen. Since the cost to prolong the repair project is not included in the repair cost in the study, the investment effect may be smaller than that shown in Table 9.

Figure 10 shows the annual cost of each case. While the maximum annual cost is seen at the 1 st year for all cases, the annual cost decreases gradually. In the case that the maximum budget is very small such as 1,000 thousands yen, the relatively uniform annual cost is happen.

\section{Conclusions}

The method of the asset management for the irrigation tanks was examined. Firstly, the method to evaluate the risk of breach due to downpour was introduced. Then, the reduction of the risk by repair was estimated by using the risk evaluation method. LCC of an irrigation tank considering

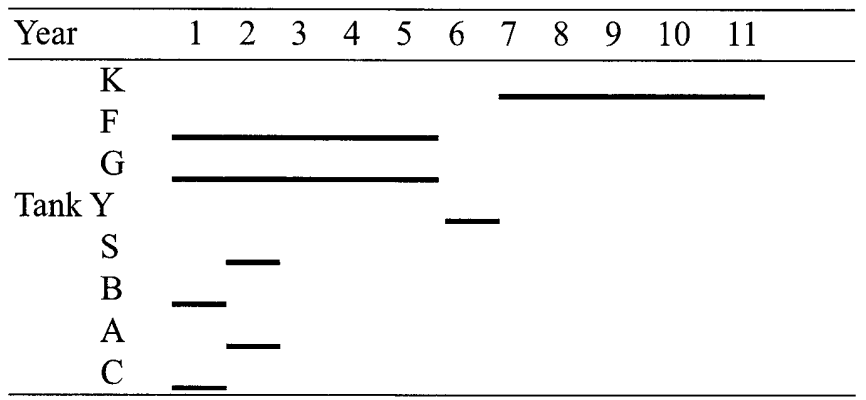

Figure 9: Schedule of repair in the maximum budget of 1,500 thousands yen

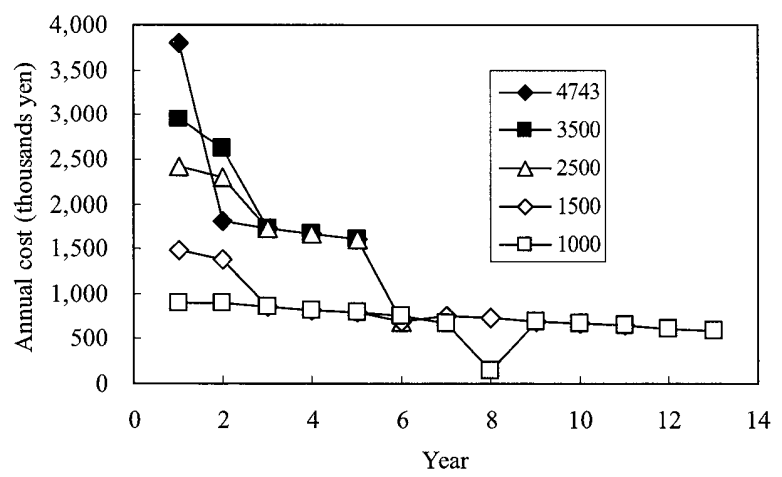

Figure 10: Annual cost of repair for each maximum budget in Case B (Caption is the maximum budget (thousands yen)) the breach due to downpour was proposed by using the failure probability, risk and repair cost. The timing of repair was examined for an irrigation tank in Awaji Island. Then, the asset management for eight tanks was studied. The followings are obtained as a result:

1) As the timing of repair is earlier, LCC at the 80th year becomes smaller. Thus, the repair of the irrigation tanks should be carried out as soon as possible. However, if the repair cost is relatively high, the effect of repair becomes small.

2) As the maximum budget for repair is smaller, the duration of repair becomes longer and LCC at the 80th year becomes higher. However, since the repair cost converted to the present money value becomes small, the investment effect becomes good. Although this conclusion is induced by ignoring the cost to keep the repair project for a long period, this will be possible as a general tendency.

3) The maximum annual cost of repair will be happen at the 1st year. As a tendency, the annual cost reduces gradually. If the repair of each tank is carried out in a single year, the uniform budget can be planned. If the repair of some tanks is divided into multiple years, the uniform budget can be planned by reducing the budget.

\section{References}

[1] Japanese Society of Irrigation, Drainage and Reclamation Engineering, Kyoto branch (2005): Report of the disaster at Awaji Island by typhoon No. 16 in 2004. (in Japanese).

[2] Kato, T. (2005): Flood mitigation function and its stochastic evaluation of irrigation ponds, Research Report of $\mathrm{Na}$ tional Institute for Rural Engineering in Japan, No44, pp.1-22. (in Japanese).

[3] Kobayashi, A., Oka, T., Aoyama, S. and Inoue, K. (2006): Risk assessment of failure of farm pond due to downpour. Proceedings of Annual Conference of the Japan Society of Irrigation, Drainage and Reclamation Engineering, pp.812-813. (in Japanese).

[4] Kobayashi, A., Yamamoto, Y., Oka, T and Aoyama, S.(2007): Examination of Life Cycle Cost of embankment of irrigation tank with regard to heavy down fall, Journal of Geotechnical Engineering, JSCE, C, 63(4), pp.954-962. (in Japanese).

[5] Kong, J. S. and Frangopol, D. M. (2003): Evaluation of expected Life-cycle maintenance cost of deteriorating structures, Journal of Structural Engineering, pp.682-691.

[6] Ministry of Agriculture, Forestry and Fisheries of Japan (1985): Coefficients which are necessary for the measurement of the economic effect in the reclamation project. (in Japanese).

[7] Ministry of Land, Infrastructure, Transport and Tourism (2004): Technical guideline of cost and benefit analysis for public projects. (in Japanese).

[8] Odasawa, T., Ishihara, K., Kobayashi, K. and Kondo, Y. (2004): Optimal repair strategies reference to economical life expectancy, Journal of Infrastructure Planning and Management, No.772, VI-65, pp.169-184. (in Japanese).

Discussion open until June 30, 2009 